\title{
Polycomb repressive complex 1 activities determine the columnar organization of motor neurons
}

\author{
Molly G. Golden and Jeremy S. Dasen ${ }^{1}$ \\ Department of Physiology and Neuroscience, Smilow Neuroscience Program, Howard Hughes Medical Institute, New York \\ University School of Medicine, New York, New York 10016, USA
}

\begin{abstract}
Polycomb repressive complexes (PRCs) establish and maintain gene repression through chromatin modifications, but their specific roles in cell fate determination events are poorly understood. Here we show an essential role for the PRC1 component Bmil in motor neuron (MN) subtype differentiation through dose-dependent effects on $H o x$ gene expression. While Bmil is dispensable for generating MNs as a class, it has an essential role in specifying and determining the position of Hox-dependent MN columnar and pool subtypes. These actions are mediated through limiting anterior Hox expression boundaries, functions deployed in post-mitotic MNs, temporally downstream from morphogen gradients. Within the $\mathrm{Hox} C$ gene cluster, we found a progressive depletion of PRC-associated marks from rostral to caudal levels of the spinal cord, corresponding to major demarcations of $\mathrm{MN}$ subtypes. Selective ablation of Bmil elicits a derepression of more posterior $H o x$ genes, leading to a switch in $M N$ fates. Unexpectedly, Hox patterns and MN fates appear to be sensitive to absolute PRC1 activity levels; while reducing Bmi1 switches forelimb lateral motor column (LMC) MNs to a thoracic preganglionic (PGC) identity, elevating Bmil expression at thoracic levels converts PGC to LMC MNs. These results suggest that graded PRC1 activities are essential in determining $M N$ topographic organization.
\end{abstract}

[Keywords: Hox; epigenetics; motor neuron; polycomb; spinal cord]

Supplemental material is available for this article.

Received June 21, 2012; revised version accepted August 10, 2012.

The Polycomb group (PcG) is a large protein family that plays a variety of crucial roles in animal development. The depth of its involvement is highlighted by the copious number of genes that are bound by PcG members or bear histone modifications indicative of PcG-mediated repression (Boyer et al. 2006; Bracken et al. 2006; Lee et al. 2006). The function of the PcG in CNS maturation, however, remains unclear and may be dependent on temporal and spatial context. PcG complexes play somewhat disparate roles regulating cell fate decisions in several proliferating CNS populations. The PcG member Bmil in particular has been examined for its multifaceted role in modulating stem cell identity during development. The self-renewal capacity of neural stem cell populations, but not progenitor populations, is dependent on Bmil, indicating that PcG pathways are key in distinguishing stem-like neural proliferation from developmental proliferation (Molofsky et al. 2003). Furthermore, overexpression of Bmil only facilitates proliferation in stem cell populations expressing FoxG1 in the forebrain, where it

${ }^{1}$ Corresponding author

E-mail jeremy.dasen@nyumc.org

Article is online at http://www.genesdev.org/cgi/doi/10.1101/gad.199133.112. specifies production of neurons rather than glia (Fasano et al. 2009). PcG complexes have been found to have an inverse function in neocortical progenitors, where PcG members facilitate the transition from neuron to astrocyte production (Hirabayashi et al. 2009). Similarly, PcG activity can influence the generation of spinal dorsal interneurons via regulation of BMP signaling (Akizu et al. 2010).

Outside the nervous system, PcG complexes have been shown to contribute to developmental patterning via their interaction with Hox genes, which broadly govern regional morphology and cellular identity over the body axis (Mallo et al. 2010). PcG genes were first discovered as regulators of body plan and Hox expression in Drosophila (Lewis 1978; Struhl 1981; Jurgens 1985). Drosophila larvae with loss of function for the Bmi1 homolog Posterior sex combs (Psc) express $\mathrm{AbdA}$ and $\mathrm{AbdB}$ rostral to their normal boundaries (Simon et al. 1992; Martin and Adler 1993), leading to the transformation of several body segments into more posterior segments (Jurgens 1985; Brunk et al. 1991; van Lohuizen et al. 1991). Later work has demonstrated conservation of this role in mammals. Removal of Bmi1 leads to rostral shifts in the expression of Hox genes within the mesoderm as well rostral shifts in vertebral morphology (van der Lugt et al. 1994, 1996), 
while overexpression of Bmil results in the inverse phenotype (Alkema et al. 1995).

The central role that PcG complexes play in the establishment of cellular identity is significant due to the heritability of PcG-induced repression over multiple cellular divisions. While the precise mechanism of PcGmediated silencing is unclear, the histone modifications deposited by PcG complexes are associated with compacted, silent chromatin. Classically, PcG repression in Drosophila is thought to be mediated by a two-step process (Simon and Kingston 2009). Polycomb reprssive complex 2 (PRC2) initiates repression by binding to a Polycomb response element (PRE), where it trimethylates Lys 27 on histone 3. This modification (H3K27me3) can be bound by the chromodomain found in PRC1, a complex that maintains repression of the locus and monoubiquitinates Lys 119 of histone H2A. While this model of two-step recruitment of PRC2 and PRC1 complexes is relevant in vertebrates, the behavior of PcG complexes is much more diverse. It is unclear how initial recruitment of PcG complexes occurs at mammalian loci, as only a handful of PREs have been found (Sing et al. 2009; Woo et al. 2010); however, PRC binding at several mammalian loci is regulated by noncoding RNA-binding partners (Rinn et al. 2007; Zhao et al. 2008; Khalil et al. 2009; Yap et al. 2010). There is also some evidence that PRC1 can function independently of PRC2 or that the two complexes costabilize the binding of one another (Simon and Kingston 2009). Within mammalian Hox loci, it seems likely that PRC1 and PRC2 are both involved in mediating correct patterns of repression via either a classical hierarchical recruitment model or costabilization. Work characterizing the distribution of PcG members and associated histone marks across the genome in embryonic stem (ES) and fibroblast cells has shown concomitant binding of PRC1, H3K27me3, and PRC2 at Hox loci (Boyer et al. 2006; Bracken et al. 2006; Woo et al. 2010).

While the role of PRCs in controlling the expression of developmental regulatory factors is well described, surprisingly little is known about their function in neuronal subtype diversification. In the embryonic spinal cord, Hox transcription factors determine the regional identity of motor neurons (MNs), raising the possibility that PcG proteins have an instructive role in their specification. In this context, Hox activities parse an initially uniform neuronal class into many subgroups with distinct postsynaptic targets. The largest subgroups are known as columns, three of which are distinguished by Hox genes expressed at specific levels of the neuraxis. At thoracic levels, Hoxc9 defines preganglionic (PGC) motor column MNs that innervate the sympathetic chain ganglia. Hoxc6 defines the lateral motor column (LMC) found at brachial levels that innervates the muscles of the forelimb, while Hoxc10 defines the LMC found at lumbar levels (Dasen et al. 2003). LMC neurons can be further subdivided into smaller Hox-dependent groups known as motor pools, each of which innervates a distinct limb muscle (Dasen et al. 2005). Thus, the patterning of Hox gene expression must be precisely regulated to ensure the establishment of a topographic registry between $\mathrm{MN}$ subtypes and their peripheral synaptic targets.
The factors governing this meticulous Hox gene code are currently not well defined. In spinal MNs, Hox patterns are thought to be regulated over two distinct phases of development. During tail bud regression and closure of the neural tube, the progenitor zone of the spinal cord is colonized by a stem cell-like population surrounding the node. These cells are exposed to retinoic acid (RA) from the rostral somitic mesoderm and fibroblast growth factors (FGFs) from the caudal presomitic mesoderm and node (Dasen and Jessell 2009). A cell remaining in the stem-like population for a longer period of time sees increased exposure to FGFs and decreased exposure to RA, resulting in a more caudal pattern of Hox gene expression upon the cell's eventual maturation as an MN.

This initial pattern of Hox expression is later refined after cells have undergone their final mitosis. At this stage, specific Hox factors display cross-repressive interactions that sharpen and maintain their expression borders (Dasen et al. 2003). Cross-repressive interactions appear to be critical to, and possibly restricted to, establishing the posterior Hox expression boundaries. For instance, in mice lacking the thoracic Hox gene Hoxc9, the more rostrally expressed Hox4-Hox8 genes are derepressed, and PGC neurons acquire an LMC fate. Analysis of histone modifications at thoracic levels indicates that Hoxc9-mediated repression is independent of the H3K27me3 mark associated with PcG-mediated repression (Jung et al. 2010). In contrast, H3K27me3 marks are found on Hox genes expressed more posteriorly, suggesting that PcG repression has a selective role in defining anterior Hox boundaries.

We show here an essential role for PRC1 function in controlling MN organization through regulation of Hox gene expression. In differentiated MNs, we observed a progressive decrease in the occupancy of PRC marks within the $\operatorname{HoxC}$ locus along the rostrocaudal axis. We found that the activities of the PRC1 component Bmil are essential in controlling the anterior limit of Hox gene expression and delineating the position of MN columnar subtypes. Attenuation or elevation of Bmil elicits a repositioning of Hox boundaries and motor columns, suggesting that MNs are sensitive to the overall levels of PRC1 activity. These actions appear to be deployed subsequent to the signaling gradients that determine the early positional identity of MN progenitors. Collectively, our results indicate that a key mechanism through which Hox gene patterns are controlled in MNs relies on the net level of PRC1 activity in early post-mitotic cells.

\section{Results}

Distribution of Polycomb-associated proteins at HoxC loci in the spinal cord

To assess a possible role for PRC activity in MNs, we first examined chromatin modifications and binding of PRC components at motor column-defining Hox loci at distinct rostrocaudal levels of the spinal cord. The H3K27me3 mark is a histone modification associated with PcG-mediated repression (Simon and Kingston 2009). Our previous studies 
provided evidence that at brachial and thoracic levels, Hox genes carry the H3K27me3 modification selectively at segments more rostral to where they are expressed (Jung et al. 2010). To assess whether this pattern of histone modifications applies generally to column-defining Hox genes at all spinal levels, we examined the distribution of H3K27me3 at cervical, brachial, thoracic, and lumbar levels (Fig. 1A,B). We also analyzed the chromatin state of Hox loci at these four spinal levels by interrogating the binding pattern of the PRC1 component Bmil as well as
H3K4me3, a mark associated with transcriptionally active genes.

We used chromatin immunoprecipitation (ChIP) assays to monitor the levels of $\mathrm{H} 3 \mathrm{~K} 27 \mathrm{me} 3, \mathrm{H} 3 \mathrm{~K} 4 \mathrm{me} 3$, and Bmi1 found near the promoter regions of Hoxc6, Hoxc9, and Hoxc10, three column-defining Hox genes expressed at brachial, thoracic, and lumbar levels of the spinal cord, respectively. To determine the functional outcome of the chromatin state of Hoxc6, Hoxc9, and Hoxc10, we also quantified mRNA levels of these genes. Spinal cords were

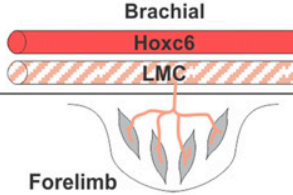

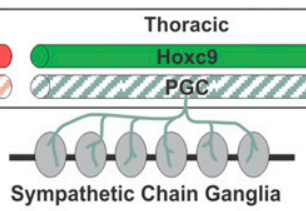

Sympathetic Chain Ganglia
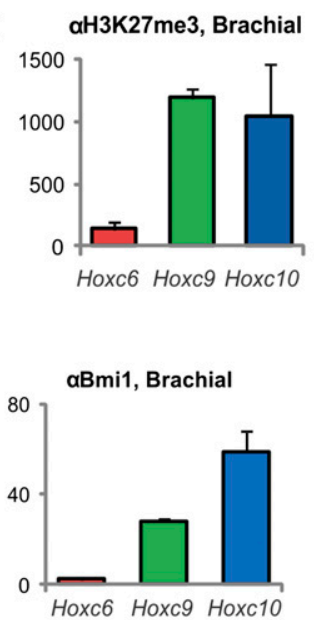

aBmi1, Cervical
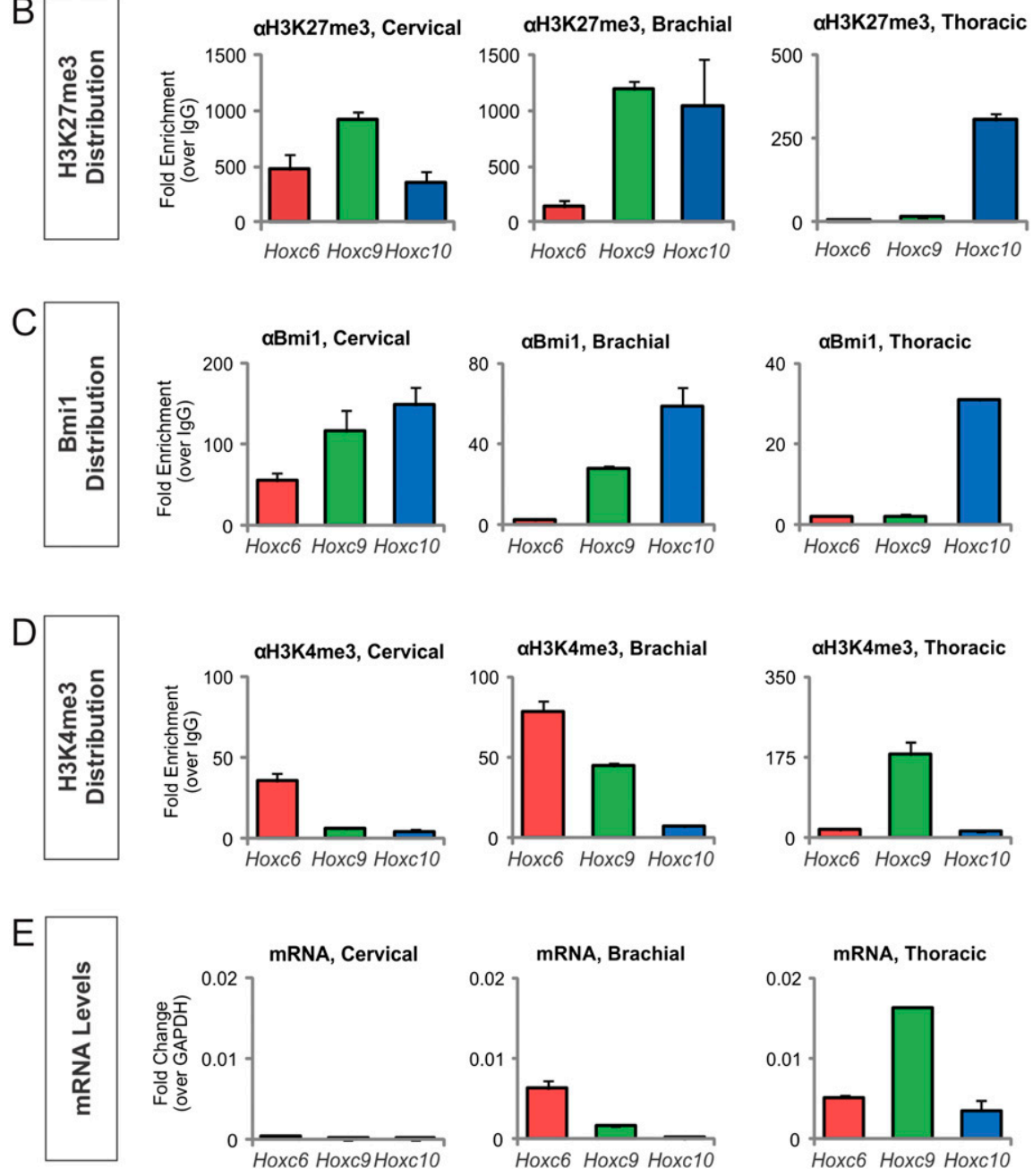
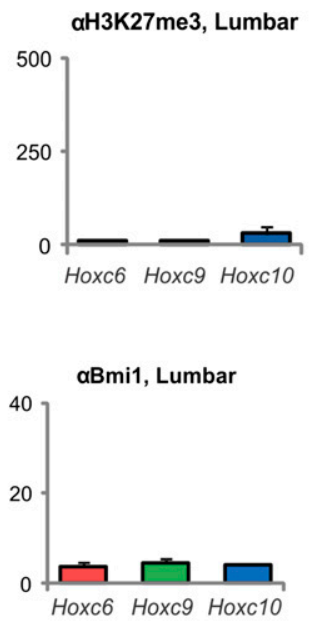

Figure 1. Chromatin marks and expression of Hox genes along the rostrocaudal axis. $(A)$ Schematic of Hox protein expression and Hox-dependent MN columnar subtypes. Rostral is to the left. LMC MNs innervate the limbs, and PGC MNs project to sympathetic chain ganglia. For simplicity, Hox-independent motor columns are not shown. (B) H3K27me3 status of Hoxc6, Hoxc9, and Hoxc10 promoter regions at cervical, brachial, thoracic, and lumbar levels. Fold enrichment is shown over IgG controls for each level. (C) Distribution of Bmil binding at columnar Hox loci shows distribution similar to that of H3K27me3. The absence of Bmil and H3K27me3 binding to lumbar chromatin indicates that antibodies specifically recognize marks at other levels. $(D)$ Distribution of H3K4me3 marks. (E) Levels of Hoxc6, Hoxc9, and Hoxc10 mRNA at each spinal level. 
isolated from Hamburger and Hamilton (HH) stage 25-27 chick embryos, a stage at which all MN columnar subtypes have been generated, and processed by collecting either chromatin or total RNA from each level. Samples were then subjected to either first strand synthesis using oligo(dT) or ChIP for H3K27me3, H3K4me3, or Bmil.

At cervical levels, none of the column-defining Hox genes were expressed, and all three Hox genes bore high levels of H3K27me3. At brachial levels, only Hoxc6 was expressed, and $\mathrm{H} 3 \mathrm{~K} 27 \mathrm{me} 3$ was found at $\mathrm{Hoxc} 9$ and Hoxc10. At thoracic levels, Hoxc9 was expressed, and H3K27me3 was only found at Hoxc10. Finally, at lumbar levels, only Hoxc10 was expressed, and H3K27me3 was not observed at any Hox gene examined (Fig. 1A,B,E). Thus, H3K27me3 is associated with Hox genes expressed more caudally than the level examined, and furthermore, Hox genes bearing high levels of H3K27me3 show low levels of transcription.

The pattern of Bmil binding to Hox loci closely follows that of $\mathrm{H} 3 \mathrm{~K} 27 \mathrm{me} 3$. At cervical levels, Bmil was bound to all three of the silenced Hox genes. At brachial levels, significant levels of Bmil were only found at the silenced Hox genes Hoxc9 and Hoxc10. Levels of Bmil binding to Hoxc9 relative to Hoxc10 appeared to be lower, however, whereas $\mathrm{H} 3 \mathrm{~K} 27 \mathrm{me} 3$ was found at both loci at roughly the same level. At thoracic levels, Bmil was bound only to the more caudally expressed Hox gene, Hoxc10. Finally, at lumbar levels, Bmil was not found in significant amounts at any Hox gene examined (Fig. 1C).

The binding patterns of $\mathrm{H} 3 \mathrm{~K} 4 \mathrm{me} 3$ to Hox loci suggest a complex interplay between chromatin modifications associated with active and repressed genes. At each level, H3K4me3 was found at the active Hox gene: At brachial levels, it was found at Hoxc6; at thoracic levels, it was found at Hoxc9; and at lumbar levels, it was found at Hoxc10 (Fig. 1D). However, H3K4me3 was also present at Hoxc6 at cervical levels and at Hoxc9 at brachial levels. These two loci also carry high levels of $\mathrm{H} 3 \mathrm{~K} 27 \mathrm{me} 3$ and Bmil, indicating that they may carry bivalent marks (Fig. 1D). The H3K4me3 mark was also observed at $\mathrm{Hoxc} 9$ at lumbar levels (Fig. 1D), while Hoxc9 mRNAs and PRC marks were not detected, suggesting a distinct mechanism of repression. Nevertheless, these data indicate that there is a progressive depletion of PRC-associated marks at Hox loci along the rostrocaudal axis and that all columndefining Hox genes bearing PRC marks are repressed.

\section{Bmi1 is dispensable for generating MNs as a class}

To determine the role of PcG complexes in specifying Hox-dependent MN subtypes, we assessed the function of Bmi1, a well-defined PRC1 component. Bmi1 has been shown to regulate rostrocaudal positional identity in the mesoderm of mice, and mutants display a one- to twosegment rostral shift in Hox expression (van der Lugt et al. 1994, 1996; Alkema et al. 1995). We hypothesized that similar shifts within the spinal cord of Bmi1 mutant mice might disrupt the specification of MN columnar subtypes. Analysis of Bmi1 mutants at embryonic day 12.5 (E12.5) showed that spinal morphology and expression of the transcription factors $\mathrm{Hb} 9$ and Isl1/2 were normal, indicating Bmil is not required for MN generation. We also observed a rostral shift in Hoxc9 expression in the dorsal spinal cord, but this did not translate to a significant change in MN identity (Supplemental Fig. S1). These results indicate that in mice, the loss of Bmi1 alone does not impact the specification of MN subtypes.

In mammals, several homologs of Bmil have been identified, including Mel-18 (Schuettengruber and Cavalli 2009). Mel-18 knockout mice display a phenotype similar to Bmi1 mutants, while Bmi1 and Mel-18 double-knockout mice are not viable beyond E9.5, indicating that these homologs compensate for each other (Akasaka et al. 2001). The embryonic chick provides a potential system to circumvent the limitations of studying Bmil/Mel-18 function for several reasons. First, the accessibility of the chick spinal cord allows acute and selective depletion of genes of interest via in ovo electroporation, avoiding the confounding side effects of global morphological distortions stemming from segmentation defects in the mesoderm and skeleton. Second, Mel-18 has not been described in the chick, and the potential lack of a functional Bmil homolog in the spinal cord avoids the issue of compensation.

We depleted Bmi1 via in ovo electroporation of dsRNAs at $\mathrm{HH}$ stage $13 / 14$, a stage in which the neural tube contains exclusively progenitors, and analyzed embryos $3 \mathrm{~d}$ later (around stage 27). A constitutive nuclear lacZ construct was included to label the region that incorporated dsRNA. Electroporation of Bmi1 dsRNA led to a marked depletion of Bmil protein within electroporated neurons (Fig. 2A). In contrast, electroporation of a scrambled dsRNA had no effect on Bmil or Hox expression patterns (Supplemental Fig. S2). To ensure that phenotypes seen after Bmil depletion were specific to PRC1 function, we assessed expression levels of PRC2-associated marks. Neither global H3K27me3 nor embryonic ectoderm development (Eed) levels were altered (Fig. 2B), indicating that Bmi1 depletion selectively affects PRCl.

We further characterized the temporal dynamics of Bmil depletion by analyzing different time points following dsRNA electroporation. At $8 \mathrm{~h}$ following electroporation (around stage 16/17), there was no depletion of Bmil protein in the electroporated spinal cord (Fig. 2E). However, after $28 \mathrm{~h}$ (around stage 18/19, as post-mitotic MNs appear), Bmil protein expression was reduced by $75 \%-$ $80 \%$. After $60 \mathrm{~h}$, we observed some recovery in Bmil levels (Fig. 2E). Nevertheless, electroporation of Bmi1 dsRNA results in the depletion of Bmil protein during the key period of $\mathrm{MN}$ specification.

To characterize the effect of Bmil loss, we first assessed expression of markers for general features of MN identity. MNs originate in the central progenitor zone of the spinal cord at a specific dorso-ventral position defined by expression of Olig2, Nkx6.1, and Pax6 (Jessell 2000; Shirasaki and Pfaff 2002). Patterning of MN progenitors was unaffected after depletion of Bmil (Fig. 2D). Post-mitotic MNs can be distinguished by the expression of $\mathrm{Hb} 9$, Isl1/2, and Lhx3. Expression of these factors is unchanged in the absence of Bmil (Fig. 2C). PRC1 function therefore does not appear to be necessary for generating MNs as a class. 


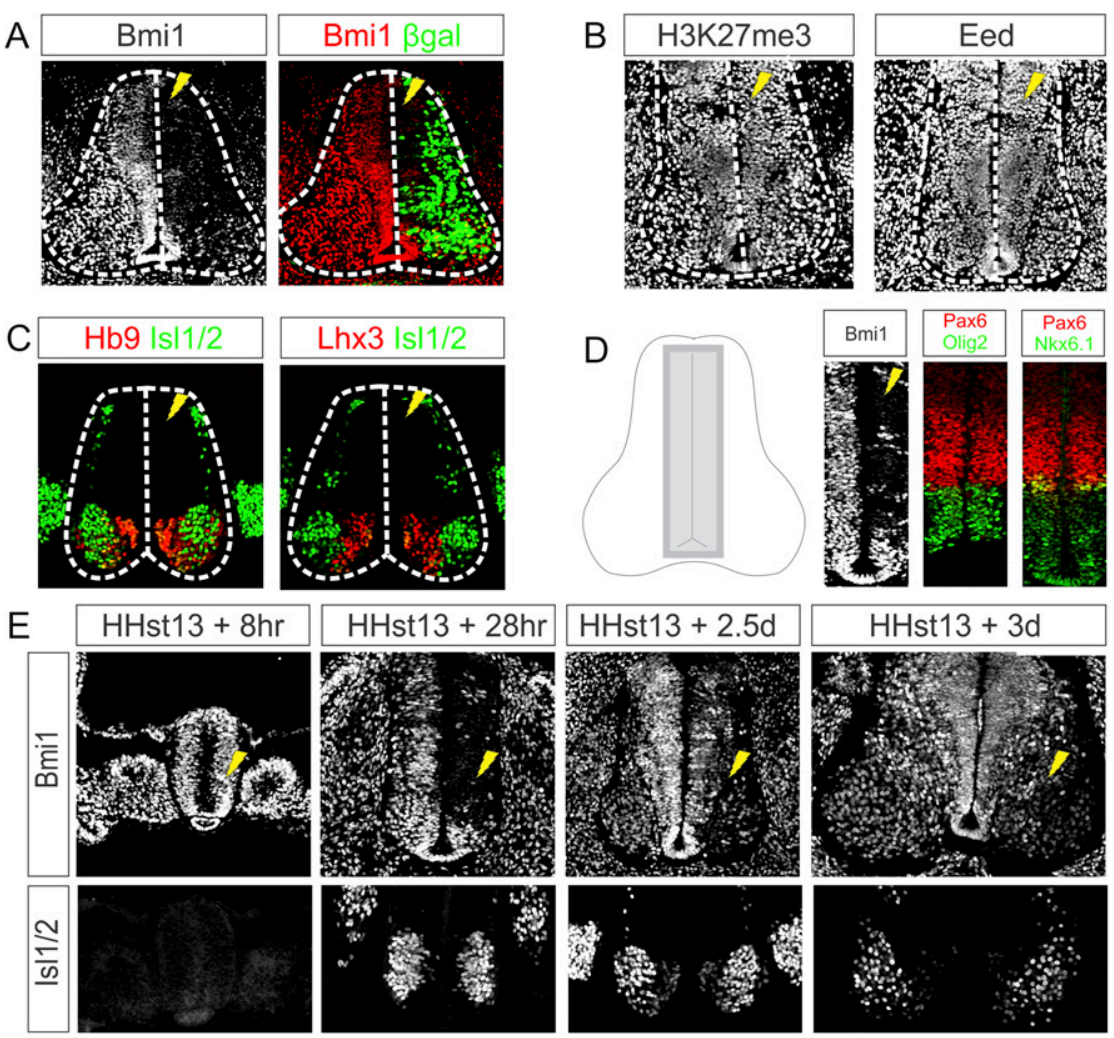

Figure 2. Bmil depletion does not affect generation of MNs. (A) Expression of Bmil is diminished upon electroporation of Bmi1 dsRNA. The electroporated half of the cord is indicated by a bolt. A nuclear LacZ construct was coelectroporated to grossly mark the electroporated region. (B) Expression of $\mathrm{H} 3 \mathrm{~K} 27 \mathrm{me} 3$ and Eed is not affected by Bmi1 dsRNA. (C) Expression of post-mitotic MN markers $\mathrm{Hb} 9$ and Isl1/2 is also not affected. (D) Expression of Olig2, Pax6, and Nkx6.1 in MN progenitors is unaffected. $(E)$ Time line of Bmil depletion upon electroporation of dsRNA at $\mathrm{HH}$ stage 13. Embryos were fixed and analyzed for Bmil expression at different time points following electroporation. Expression of Isl1/2 marks post-mitotic MNs.
Bmi1 is required for proper Hox boundaries in the spinal cord

We next analyzed the effect of Bmil depletion on Hox expression. Hoxc9 is normally expressed at thoracic levels and restricted from brachial MNs. In embryos electroporated with Bmi1 dsRNA, we observed a marked derepression of Hoxc9 at brachial levels (Fig. 3A-D). Hoxc9 was ectopically expressed rostral to its endogenous domain, extending to mid-brachial levels (Fig. 3A,H,I; data not shown). As a central regulator of Hox patterning, Hoxc9 represses the expression of Hoxc6 (Dasen et al. 2003). Consistent with this repressive function, Hoxc6 was extinguished in $96 \%$ of ectopic Hoxc9 MNs such that the overall Hox topography of the thoracic region was extended rostrally (Fig. 3E-G; Supplemental Table S1).

We next determined whether Bmil was required for regulation of Hox expression at other levels of the spinal cord. We first examined the effect of Bmil depletion on Hox expression at the thoracic-lumbar interface. Here we observed a derepression of Hoxc10 and Hoxd10, two Hox genes normally restricted to lumbar levels (Fig. 3J-M,Q,R). Similar to the effects of Hoxc9 derepression, ectopic Hoxc10 and Hoxd10 resulted in the repression of Hoxc9 (Fig. 3N-P). However, although we found similar levels of Bmil depletion, Hox10 genes were less effectively derepressed in MNs, with most ectopic cells found in the dorsal spinal cord (Fig. 3Q). Bmil depletion at the cervicalbrachial interface was ineffective at producing a rostral shift in Hoxc6 expression (data not shown), likely due to relatively high PRC activities at this level. Nevertheless, these results suggest that PRC1 functions to repress posterior Hox genes generally, with the most pronounced effects on Hoxc9 expression.

\section{Bmi1 is necessary for the development of $M N$ topography}

We next assessed whether changes in Hox patterns induced by Bmi1 depletion resulted in transformations of $\mathrm{MN}$ columnar identity. Brachial MNs can be defined by expression of Raldh2 and high FoxP1 levels, while thoracic PGC MNs are selectively labeled by $\mathrm{pSmad} 1 / 5 / 8$ (Dasen et al. 2008). After Bmil depletion, we observed an ablation of the LMC, as assessed by loss of Raldh2 and FoxP1 expression (Fig. 4A-D). In addition, ectopic $\mathrm{pSmad}^{+}$ MNs were detected in $25 \%$ of the Hoxc $9^{+}$MNs at brachial levels, demonstrating a transformation to a PGC fate (Fig. 4E,F; Supplemental Table S1). In contrast, expression of Lhx3 and $\mathrm{Hb} 9$ in axial projecting medial motor column (MMC) neurons was unchanged (Fig. 4G,H). Loss of Bmil at brachial levels therefore results in the derepression of Hoxc9, leading to a loss of LMC identity and the respecification to a PGC fate, indicating a selective effect on Hox-dependent MN subtypes (Fig. 4I).

The brachial LMC can be further subdivided into smaller MN groups, known as motor pools. Hox genes are differentially expressed within the LMCs and define codes for pool fates (Dasen et al. 2005). We asked whether the transformations in MN identity elicited by Bmil depletion also affected motor pool organization. Staining for the brachial Hox genes Hoxa5, Hoxc6, and Hoxc8 

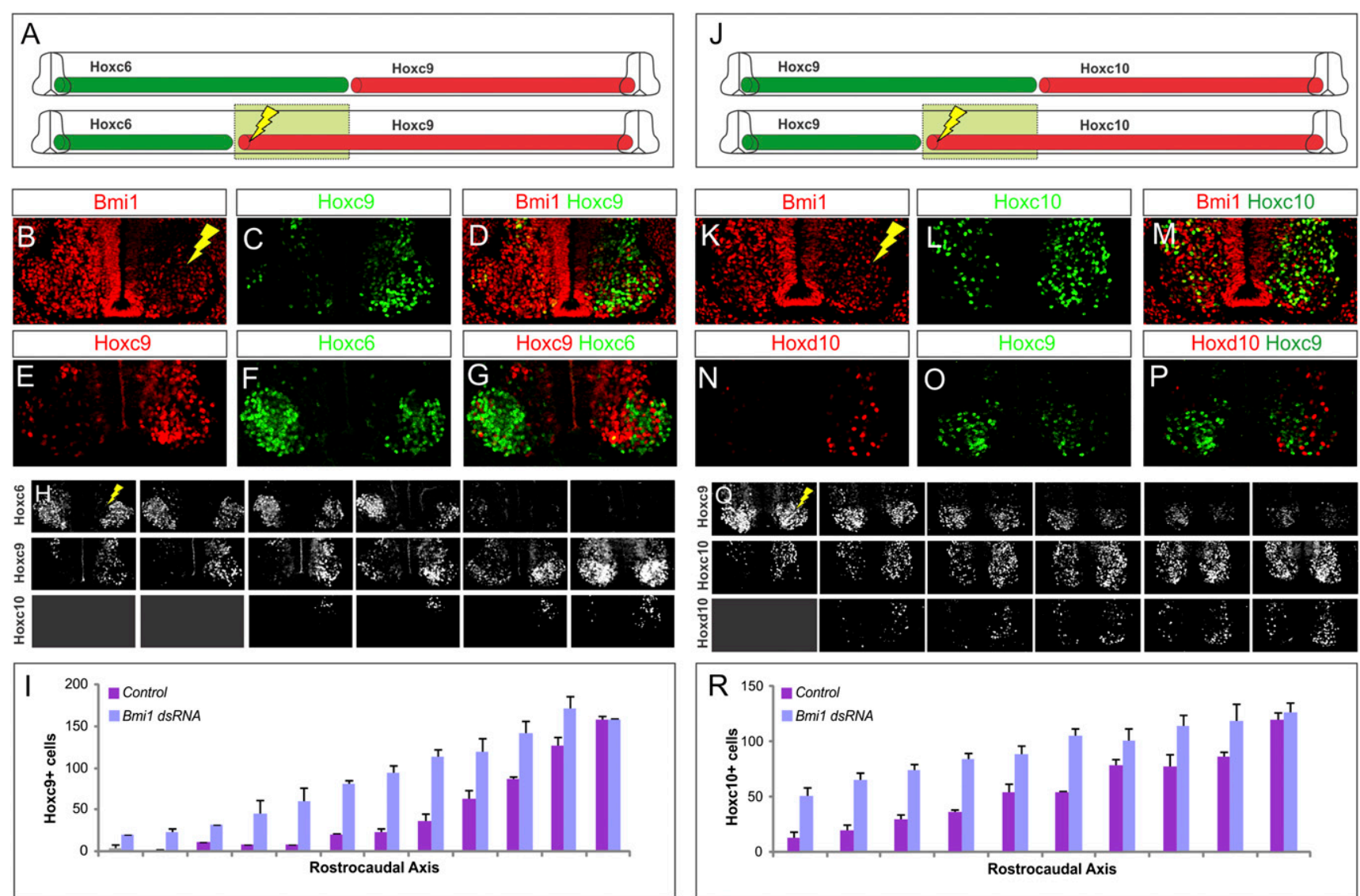

Figure 3. Effect of Bmil loss on Hox patterns in spinal MNs. (A) Summary of the effects of Bmil depletion at brachial levels. (B-D) Hoxc9 extends to brachial levels after Bmi1 depletion. $(E-G)$ Hoxc6 is repressed in cells that express Hoxc9. (H) Serial sections showing extension of Hoxc9 and loss of Hoxc6. There is no change in Hoxc10 in MNs, although some Hoxc10 cells are observed in dorsal regions. Results shown are typical of electroporations where $>80 \%$ of cells have lost Bmil. (I) Quantification of Hoxc9 ${ }^{+}$cells along the rostrocaudal axis of the electroporated and nonelectroporated halves of chick spinal cord $\mathrm{HH}$ stages 25-28. Results show averaged cell counts from two embryos. Error bars show standard error. (J) Effects of Bmi1 loss at thoracic/lumbar levels. (K-N) Hoxc10 and Hoxd10 are derepressed. $(O, P)$ Ectopic Hoxd10 cells do not express Hoxc9. (Q) Serial section showing extension of Hox 10 proteins and loss of Hoxc9. $(R)$ Quantification of Hoxc $10^{+}$cells along the rostrocaudal axis of the electroporated and nonelectroporated halves of the spinal cord. Results show averaged cell counts from four embryos.

showed that all Hox genes underwent a rostral shift in their expression (Supplemental Fig. S3). We also assessed two Hox-dependent motor pools, identified by their expression of the transcription factors Scip and Pea3 (Dasen et al. 2005). These pools were eroded within their normal domains, while cells in the rostral portion of the brachial compartment (which retain an LMC fate) acquired Scip ${ }^{+}$or Pea3 ${ }^{+}$identities (Supplemental Fig. S3). Thus, Bmil actions are not restricted to motor columndefining Hox genes.

\section{MN fate switch after Bmi1 depletion causes a redirection of motor axons}

To further assess the consequences of respecifying the identity of LMC neurons, we examined the peripheral connectivity of brachial MNs lacking Bmil. Brachial LMC axons normally project ventrolaterally toward the limb bud and avoid the sympathetic chain ganglia. Consistent with this pattern, electroporation of a construct expressing GFP under the control of the $H b 9$ promoter labeled motor axons that bypass the sympathetic ganglia and project to the limb (Fig. 4J). However, when $H b 9::$ GFP was coelectroporated with dsRNA against Bmi1, the axons of caudal LMC MNs innervated sympathetic ganglia (Fig. 4J-M). Changes in Hox patterning following depletion of Bmil therefore result in the respecification of motor columns at both the level of molecular identity and peripheral connectivity.

\section{Bmi1 regulates brachial $M N$ identity through modulation of Hoxc9 gene expression}

The effects of Bmil depletion on Hoxc6 and MN organization could be mediated directly by Bmil or indirectly by changes in Hoxc9. Bmil depletion phenocopies the switch in MN fates observed after brachial Hoxc9 misexpression (Dasen et al. 2003), suggesting that the observed effects are solely due to ectopic Hoxc9. To test this, embryos were coelectroporated with dsRNAs targeting 

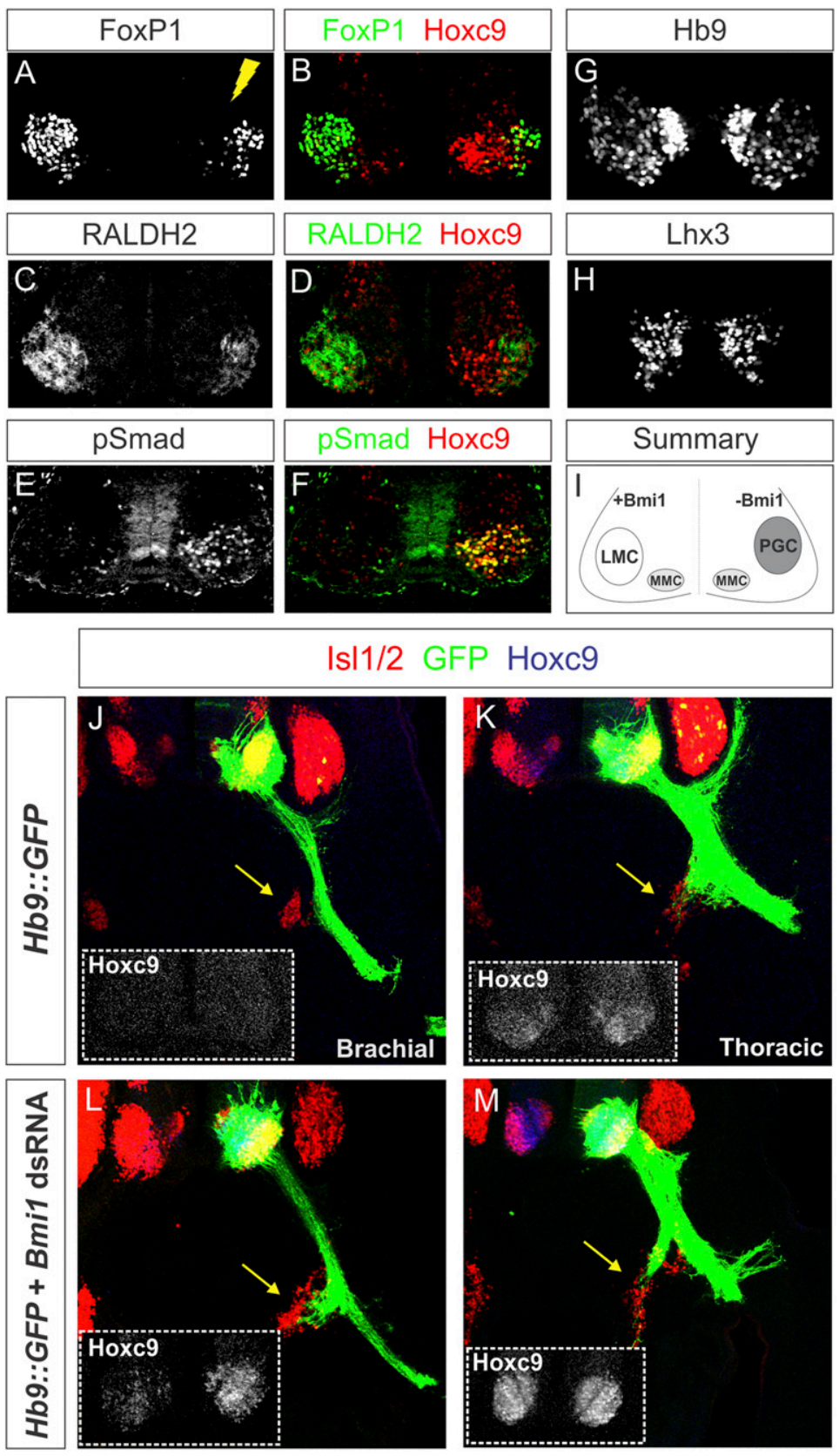

Figure 4. Bmil depletion converts forelimb LMC MNs to a PGC fate. $(A-D)$ Expression of the LMC markers FoxP1 and Raldh2 is diminished after depletion of Bmil at brachial levels. $(E, F)$ Expression of the PGC marker pSmad is detected at brachial levels and coexpresses Hoxc9. Not all ectopic Hoxc9 cells label with pSmad, as Hoxc9 is derepressed in non-MN cells. $(G, H)$ Expression of pan-MN markers $\mathrm{Hb} 9$ and Lhx3 is not affected at brachial levels. (I) Summary showing changes in MN molecular identity following Bmil depletion. $(J, K)$ Vibratome sections of chick embryos electroporated with a $H b 9:: G F P$ construct to label motor axons (green). Sympathetic chain ganglia are indicated by yellow arrows and are stained by Isl1/2. $(L, M)$ MNs coelectroporated with Bmi1 dsRNA and $H b 9:: G F P$ express ectopic Hoxc9, and their axons are redirected to the sympathetic chain ganglia at brachial levels. both Bmi1 and Hoxc9, which effectively depleted both proteins from MNs (Supplemental Fig. S4). Concurrent depletion of Bmil and Hoxc9 at brachial levels had no effect on Hoxc6 expression (Supplemental Fig. S4), consistent with the idea that Hoxc9 is necessary to repress brachial Hox genes. In addition, expression of FoxP1 in LMC MNs was not affected, and no ectopic $\mathrm{pSmad}^{+} \mathrm{MNs}$ were observed (Supplemental Fig. S4). When Bmi1 and Hoxc9 expression was reduced at thoracic levels, we observed a phenotype similar to that seen in Hoxc9 knockout mice (Jung et al. 2010); PGC MNs were lost, Hoxc6 was derepressed, and MNs acquired an LMC fate (Supplemental Fig. S4). These data indicate that the phenotypes observed in the absence of Bmil are due to the derepression of Hoxc9 and not to a direct effect of Bmil on either MN identity or other Hox genes.

\section{Bmi1 depletion does not affect Hox patterns in spinal progenitors}

The pattern of Hox expression in the spinal cord is initially controlled through opposing gradients of FGFs and RA, which act on progenitors shortly after neurogenesis (Dasen and Jessell 2009). The rostrocaudal limits of Hox expression domains are later refined post-mitotically via cross-repressive interactions with other Hox genes (Dasen et al. 2003; Jung et al. 2010). Having demonstrated that Bmil is necessary to delineate the correct 
rostral boundaries of Hox genes expressed at thoracic and lumbar levels, we next asked at which stage in development Bmil-mediated repression of Hox genes is established.

We first examined the potential involvement of Bmil in programming early Hox expression mediated by FGF signaling. From HH stages 10 to 14, neural tube progenitors express Hoxc9 mRNA and protein at thoracic levels, and elevation of FGF signaling at these stages induces rostral shifts in Hoxc9 expression, resulting in a loss of LMC MNs and a rostral extension of the PGC (Dasen et al. 2003). The similarity of the effects of elevated FGF8 to Bmi1 depletion led us to explore whether Bmil similarly regulates Hoxc9 in neural progenitors. We replicated the effects of FGF8 and analyzed embryos at a slightly later stage, demonstrating that at $\mathrm{HH}$ stage $12+24$ h, FGF8 overexpression induces a rostral shift of
Hoxc 9 mRNA and proteins in brachial neural tube progenitors but does not affect Bmil levels (Fig. 5A,C). Depletion of Bmil at $\mathrm{HH}$ stage $12+24 \mathrm{~h}$ did not show similar changes in early Hox expression patterns, as Hoxc9 was not ectopically expressed in brachial progenitors (Fig. 5B,D). Ectopic Hoxc9 expression was observed at a slightly later stage (stage $14+28 \mathrm{~h}$ ), prior to the appearance of the first brachial post-mitotic MN (Supplemental Fig. S5). These results indicate that Bmil is not necessary at the progenitor phase of $\mathrm{MN}$ development for the patterning of Hox genes mediated by FGFs.

To gain further insight into the temporal requirement for PcG complexes in restricting Hox patterns, we examined the effects of selectively depleting PRC function from MN progenitors. Ezh2 is a core component of PRC2 and is necessary for depositing $\mathrm{H} 3 \mathrm{~K} 27 \mathrm{me} 3$. To remove PRC2 function from MN progenitors, we crossed a floxed
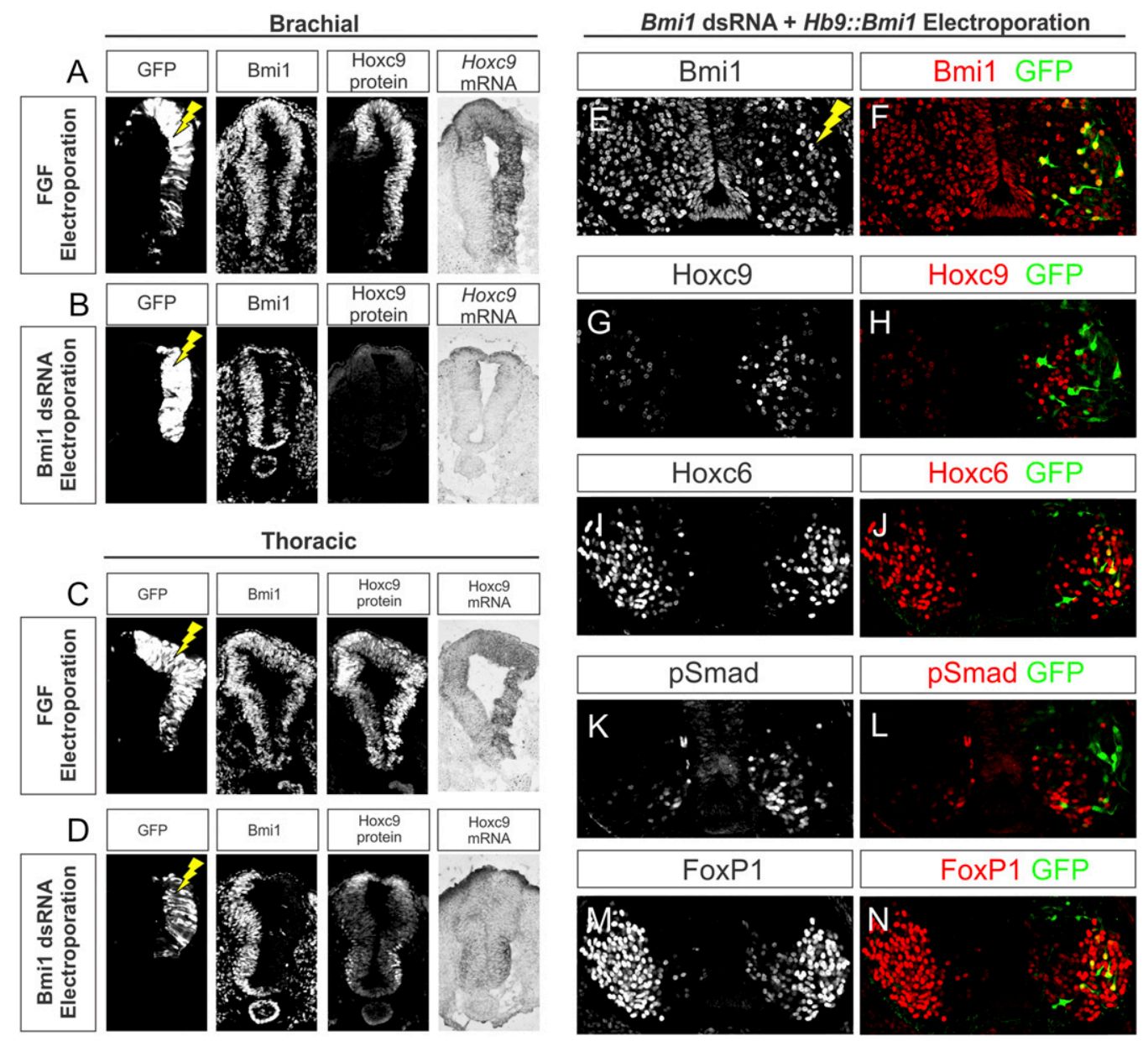

Figure 5. The developmental timing of Bmil-mediated control of Hox expression. (A) Elevation of FGF signaling induces Hoxc9 in brachial progenitors. HH stage 14 chick embryos were electroporated and analyzed after $24 \mathrm{~h}$. A GFP expression construct was coelectroporated to grossly mark the electroporated region. Bmil expression is unchanged by FGF8 overexpression. $(B)$ Effects of Bmil depletion on brachial progenitors. Hoxc9 immunostaining and in situ hybridization show that brachial Hoxc9 expression does not change in the absence of Bmil. $(C, D)$ Hoxc9 is grossly unaffected at thoracic levels after FGF elevation or Bmil depletion. $(E, F)$ Rescue of Bmil expression at brachial levels of the spinal cord. Embryos were coelectroporated with Bmi1 dsRNA and Hb9::Bmi1-ires-GFP. $(G, H)$ Expression of Hoxc9 is shifted rostrally into the brachial level on the electroporated side of the cord; however, Hoxc9 is excluded from cells rescued for Bmil. $(I, J)$ Expression of Hoxc6 is reduced on the electroporated side of the cord but is restored in rescued cells. $(K, L)$ pSmad is excluded from cells expressing GFP. $(M, N)$ Expression of FoxP1 is restored in cells expressing GFP. 
Ezh2 line (Su et al. 2003) to Olig2::Cre mice (Dessaud et al. 2007) in which Cre is expressed in MN progenitors. Analysis of global H3K27me3 levels demonstrated that while the PRC2 mark was effectively depleted from progenitors, H3K27me3 was retained in post-mitotic MNs (Supplemental Fig. S6), likely due to compensation by the Ezh2 homolog Ezh1 (Ezhkova et al. 2011). We found no change in Hox patterns or MN organization over the rostrocaudal axis after conditional ablation of Ezh2 (Supplemental Fig. S6). We conclude that PRC2 function is not necessary within progenitors for correct expression of Hox genes, further supporting a late role for PRC function.

If PRC1 activity is deployed in early post-mitotic MNs, then selective late expression of Bmil should rescue the effects of early Bmil depletion. To test this, embryos were coelectroporated with both Bmil dsRNA and an $H b 9:$ : BmiliresGFP construct and analyzed for changes in Hox expression and MN identity. Coelectroporation of these constructs at brachial levels effectively depleted levels of Bmil expression except in individual post-mitotic cells expressing Hb9::Bmi1 (Fig. 5E,F). Because of differences in the electroporation efficiency between plasmids and dsRNAs, Bmil-rescued MNs were typically surrounded by cells that lacked Bmil. In cells rescued for Bmi1, 99\% did not express Hoxc9, despite ectopic Hoxc9 expression in neighboring Bmil-negative cells (Fig. 5G,H). Furthermore,
$65 \%$ of Bmil-rescued cells expressed Hoxc6 and 38\% expressed FoxP1, but only 4\% expressed pSmad (Fig. 5I-N; Supplemental Table S1). Thus, expression of Bmil at the post-mitotic stage can cell-autonomously rescue Hox patterning and MN identity.

\section{Elevation of Bmi1 expression converts PGC MNs to an LMC fate}

Mice overexpressing Bmi1 globally are characterized by a caudal shift in the expression of Hox genes within the mesoderm as well as an accompanying anterior transformation in vertebral identity (Alkema et al. 1995), suggesting that Hox patterning along the neuraxis may be similarly sensitive to Bmil levels. In order to investigate a potential role of Bmil dosage in controlling Hox expression in MNs, we electroporated a constitutive Bmi1-ires-nuclearGFP expression vector ( $p C I G:: B m i 1)$ into both brachial and thoracic neural tubes and assessed Hox patterning and columnar specification. Quantification of nuclear Bmil levels revealed an approximately fivefold elevation in protein levels in electroporated cells. Expression of $\mathrm{Hb} 9$ and Isl1/2 remained normal under conditions of elevated Bmil, indicating that MN generation was unaffected (Fig. 6A-D; data not shown). In addition, expression of Hoxc6 in brachial LMC MNs was unaffected by Bmil elevation,
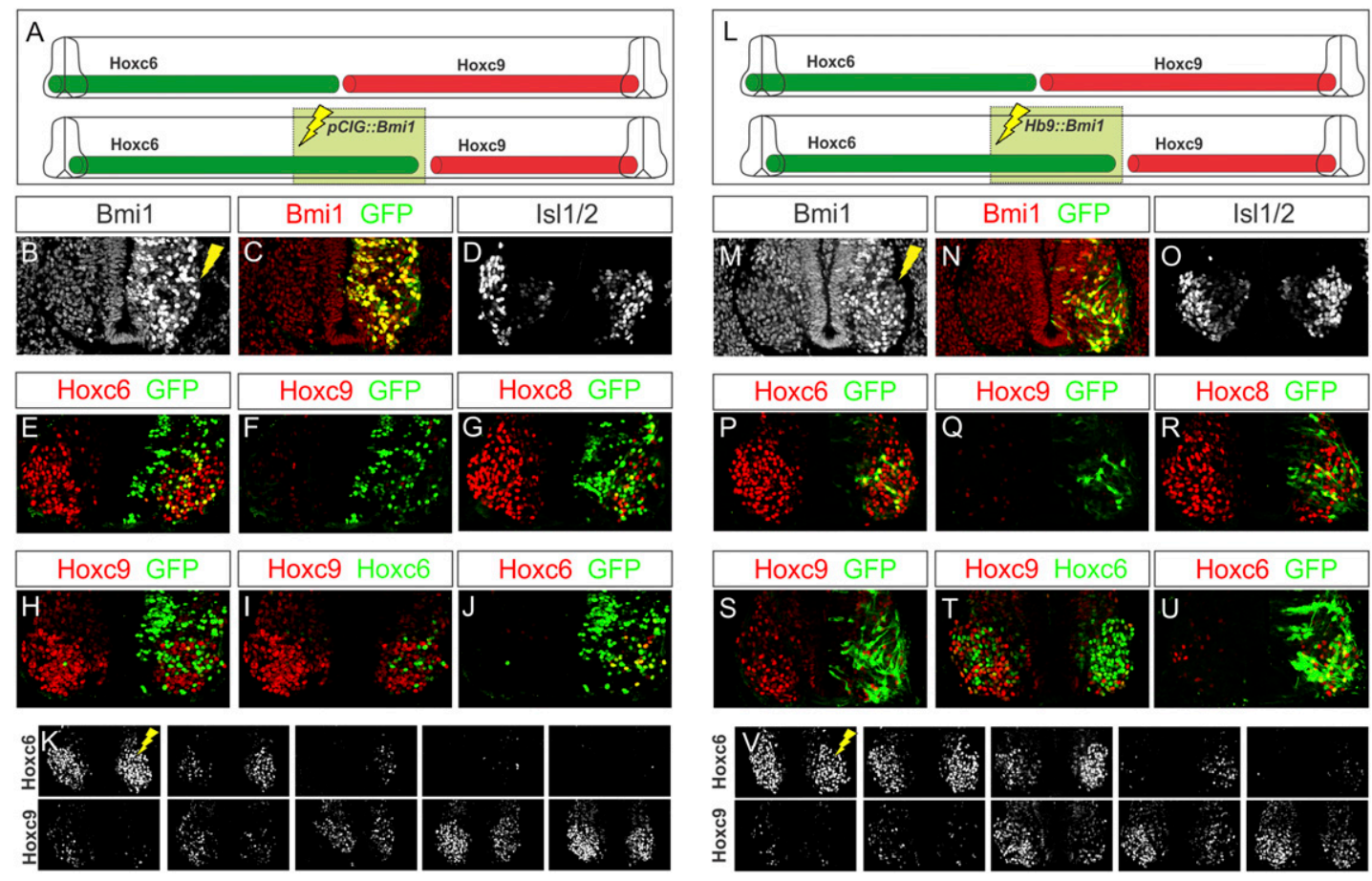

Figure 6. Elevation of Bmil expression at thoracic levels extinguished Hoxc9. (A) Schematic of the effects of Bmil elevation at thoracic levels of the spinal cord. $(B, C)$ Bmil expression is elevated after electroporation of a $p C I G:: B m i 1$ expression construct. $(D)$ Bmil elevation does not affect MN generation, marked by Isl1/2. (E-G) At brachial levels, Hoxc6 is unaffected, while Hoxc8 expression is diminished. No ectopic Hoxc9 is observed. $(H-J)$ At thoracic levels, Hoxc9 expression is ablated, and ectopic Hoxc6 is detected. $(K)$ Serial sections showing that Hoxc6 expression is not affected at brachial levels but is extended caudally. $(L-V)$ Effects of post-mitotic overexpression of Bmil using an Hb9::Bmi1-ires-EGFP expression construct. (M-O) Bmil expression is increased on the electroporated half of the embryo but not within the progenitor zone. Isl1/2 expression is unchanged. $(P-R)$ Effects of Bmil elevation on brachial Hox expression. $(S-U)$ Hoxc9 expression in $\mathrm{GFP}^{+}$cells is reduced, and ectopic Hoxc6 is observed. $(V)$ Extension of Hoxc6 to thoracic levels. 
and no ectopic Hoxc9 was detected (Fig. 6E,F). However, expression of Hoxc8 was diminished in caudal brachial LMC MNs, and these cells expressed ectopic Hoxa5 (Fig. 6G; data not shown). At thoracic segments, cells expressing high levels of Bmil displayed a marked decrease in Hoxc9, and MNs lacking Hoxc9 ectopically expressed Hoxc6 (Fig. 6H-K; Supplemental Table S1). These results, in conjunction with the effects of Bmil depletion, suggest that a subset of Hox genes is sensitive to Bmil levels.

To further characterize the effects of elevated Bmil expression, we analyzed motor column specification and peripheral connectivity. At brachial levels, Bmil elevation did not affect motor column identity, as assessed by FoxP1 and Raldh2 expression, consistent with a preservation of Hoxc6 expression (data not shown). However, at thoracic levels, pSmad expression was ablated, and MNs ectopically expressed high FoxP1 levels and Raldh2, indicating a transformation of the PGC into an LMC identity (Fig. 7A-D; Supplemental Table S1). The fate switch observed after Bmil overexpression was reflected in the projection patterns of MNs overexpressing Bmil, which failed to innervate the sympathetic chain ganglia (Fig. 7E$\mathrm{H})$. Thus, elevation of Bmil levels has the inverse effect of Bmil depletion, leading to a caudal shift in Hox expression and a transformation of MN identity.

We further reasoned that if Bmil acts post-mitotically to regulate $\mathrm{MN}$ identity, then late elevation of Bmil levels should recapitulate the phenotypes observed when $\mathrm{Bmil}$ is overexpressed indiscriminately within the spinal cord. We therefore electroporated $H b 9:: B$ miliresGFP and evaluated $\mathrm{MN}$ development. As with $p C I G:: B m i 1$, expression of $\mathrm{Hb} 9$ and $\mathrm{Is} 11 / 2$ were unaffected, indicating normal MN generation (Fig. 6L-O; data not shown). At brachial levels, there was no change in Hoxc6, and LMC identity was retained, although Hoxc8 expression was diminished (Fig. 6P-R). At thoracic levels, electroporated cells extinguished Hoxc9 and expressed Hoxc6 (Fig. 6S-V). Additionally, post-mitotic Bmil overexpression ablated the PGC, thoracic MNs acquired an LMC fate, and motor axons bypassed the sympathetic ganglia (Fig. 7I-P). Thus, $H b 9:: B m i 1$ embryos displayed the same Hox and columnar transformation phenotypes as those expressing elevated Bmil throughout the spinal cord, providing supporting evidence that Bmil activity regulates Hox expression post-mitotically.

\section{Bmi1 expression overrides the effects of FGF signaling on MN organization}

Although the levels of Bmil are normally homogeneous throughout the spinal cord (see Supplemental Fig. S6), Bmil gain and loss of function elicit complimentary phenotypes, suggesting that Hox genes may be sensitive to PRC1 activity levels at the time of MN differentiation. Because Hox patterns are initially controlled through signaling gradients that vary over the rostrocaudal axis, we next set out to further define the epistatic relationship between FGF signaling and levels of PRC1 activity. Two lines of evidence indicate that Bmil acts independently of FGF to control Hox patterns. First, while elevation of FGF at brachial levels induces Hoxc9 in progenitors, removal of Bmil fails to do so, suggesting that Bmil acts temporally downstream from FGF. Second, manipulation of Bmil levels under the $\mathrm{Hb} 9$ promoter is capable of switching Hox patterns in MNs, suggesting that PRC1 actions are deployed near the time of MN differentiation. These observations suggest a model in which PRC1 activities at Hox loci along the rostrocaudal

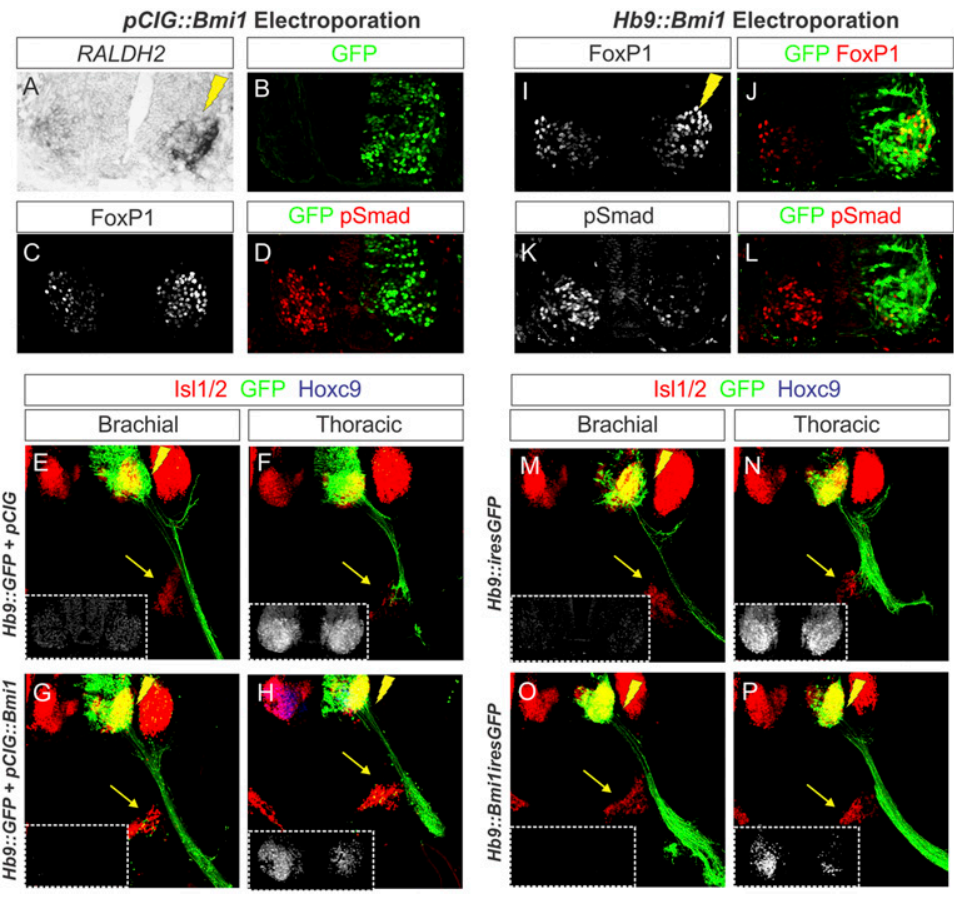

Figure 7. Effects of Bmil elevation on MN columnar identity. $(A-D)$ Effects of Bmil elevation on MN columnar identity at thoracic levels. LMC markers Raldh2 and (high) FoxP1 are ectopically expressed, while pSmad expression is extinguished. $(E, F)$ Vibratome sections of chick embryos electroporated with $H b 9:: G F P$ construct to label motor axons (green). Sympathetic chain ganglia are indicated by yellow arrows. $(G, H)$ MNs coelectroporated with $p C I G:: B m i 1$ have reduced Hoxc9 expression, and their axons are directed away from the sympathetic chain ganglia. $(I-L)$ Effects of $H b 9:: B m i 1$-ires-EGFP electroporation at thoracic levels. FoxP1 expression is elevated, while pSmad expression is reduced. $(M-P)$ Vibratome sections of chick embryos electroporated with Hb9-GFP construct to label motor axons (green). Sympathetic chain ganglia are indicated by yellow arrows. MNs coelectroporated with $H b 9:: B m i 1$-ires-EGFP have reduced Hoxc9 expression, and their axons are redirected away from the sympathetic chain ganglia. 
axis are established subsequent to the initial patterns controlled by morphogens.

If PRC1 activities are set downstream from FGF, then elevation of Bmil levels might be sufficient to "reprogram" changes in Hox expression patterns elicited by elevated FGF8. We therefore tested whether the rostral shift in Hoxc9 expression induced by FGF8 could be overcome by coexpressing Bmil. We coelectroporated $C M V:: F G F 8$ with $p C I G:: B m i 1$ and assessed Hox patterns and $M N$ fate specification. Consistent with previous studies, expression of FGF8 alone abolished Hoxc6 and FoxP1 expression and induced Hoxc9 at brachial levels (Fig. 8A). After coexpression of FGF8 and Bmi1, we found that Hoxc6 and FoxP1 were effectively rescued in $\sim 30 \%$ of cells that ectopically expressed Bmil and that these cells lacked Hoxc9 (Fig. 8B; Supplemental Table S1). Because of the non-cell-autonomous nature of the FGF8mediated conversion, rescued cells were typically surrounded by cells that expressed ectopic Hoxc9. These results demonstrate that expression of Bmil is sufficient to cell-autonomously erase the positional identity imposed on progenitor cells by early signaling gradients.

\section{Discussion}

PRCs are thought to contribute to the molecular memory of developmental programs by ensuring that certain genes remain silenced long after the disappearance of early patterning signals. While Hox genes are well-defined targets of PRC activities, the mechanisms and timing of their contributions to Hox regulation during neuronal specification are poorly defined. Our studies suggest that Hox-dependent MN subtypes are sensitive to Bmil levels at the time of their differentiation, and altering Bmil activity in vivo is sufficient to interconvert the fates of LMC and PGC neurons. The apparent sensitivity of certain Hox genes, such as Hoxc9, to Bmil levels indicates that one feature of PRC function is to set and maintain the anterior limits of key Hox genes at the interface between columnar subtypes. We discuss these findings in the context of the developmental regulation of Hox genes and suggest possible mechanisms of PRC actions in restricting Hox patterns during $\mathrm{MN}$ differentiation.

\section{Control of Hox expression in the developing spinal cord by PRC1}

Analysis of the genomic binding profiles of PRC components in ES cells suggests a central role in the control of a large repertoire of developmentally critical genes (Boyer et al. 2006; Bracken et al. 2006; Lee et al. 2006). In this study, we found a more restricted role for the core PRC1 component Bmil in the organization of $\mathrm{MN}$ subtypes along the rostrocaudal axis. Ablation of Bmil expression has no affect on progenitor patterning or the differentiation of MNs as a class and is not required in MN columns that are specified independent of Hox function, such as the MMC. In contrast, Bmil activities are necessary for the segregation of limb-innervating LMC MNs from thoracic PGC neurons. We found that manipulation of Bmil levels can switch the fates of MNs at brachial and thoracic levels of the spinal cord, leading to alterations in their molecular identity and peripheral connectivity. These results indicate that PRC1 has a critical but selective function in MN subtype specification.

The actions of Bmil in MN differentiation are mediated through their effects on Hox genes and are distinct from regulatory interactions previously shown to influence Hox expression in the spinal cord. Hox patterns are known to be set during two phases of regulation in progenitors and early post-mitotic neurons. Initially, gradients of FGFs and RA install a rough pattern of future Hox expression during formation of the neural tube, a pattern later refined through cross-repressive interactions (Dasen and Jessell 2009). At the brachial-thoracic interface, the repressive actions of Hoxc9 are known to be essential in defining the posterior boundary of Hoxc6 as well as excluding Hox4-Hox 8 gene paralogs from thoracic levels (Jung et al. 2010). The absence of the PRC-associated mark

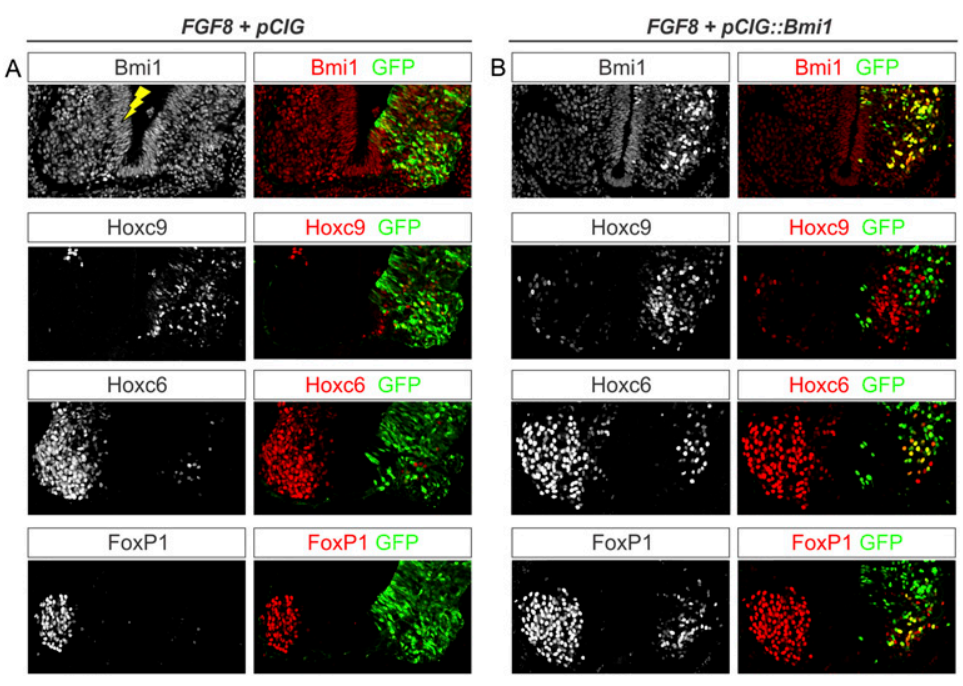

Figure 8. PRC1 reprogramming of early Hox patterning. (A) Effects of elevating FGF8 at brachial levels. Hoxc9 is expressed ectopically at brachial levels on the electroporated side of the cord, while expression of Hoxc6 is ablated. Expression of FoxP1 is also ablated. $(B)$ Effects of $p C I G:: B m i 1$ and $C M V:: F G F 8$ coelectroporation. Bmil expression levels are increased in the electroporated cells. Hoxc9 is expressed ectopically at brachial levels, except in cells expressing Bmil/GFP. Expression of Hoxc6 is reduced at brachial levels, but cells expressing Bmil/GFP are rescued for Hoxc6. Likewise, expression of FoxP1 is reduced at brachial levels but rescued in cells expressing Bmil. 
at Hox genes repressed by Hoxc9, however, indicates that this repressive event does not require PRC function.

Our results indicate that PRC activities are used to selectively delimit the anterior extent of Hox expression in MNs. We found that at a given segmental level, Hox genes expressed at more caudal regions are characterized by the presence of PRC marks (Fig. 9A). At brachial levels, the Hoxc 9 gene bears the H3K27me3 mark and is occupied by Bmil, suggesting PRC1 function may be required for its exclusion. Consistent with this idea, depletion of Bmil at brachial levels leads to ectopic Hoxc9 rostral to its normal boundary. Under these conditions, the loss of Hoxc6 from brachial MNs appears to be a consequence of ectopic Hoxc9, since combined depletion of Bmil and Hoxc9 preserves Hoxc6 and LMC specification (Fig. 9A). These findings indicate that PRC1 activities are integrated with Polycomb-independent Hox cross-repression to ensure the establishment of proper Hox boundaries in MNs.

\section{Timing of PRC actions in MN development}

While the chromatin marks deposited by PRC2 in all three germ layers are sequentially removed from Hox loci at early stages of development (Soshnikova and Duboule 2009), our data suggest a relatively late role for PRC1 in controlling the final pattern of Hox protein expression.

\section{A Effects of PRC1 manipulations at the brachial-thoracic interface}
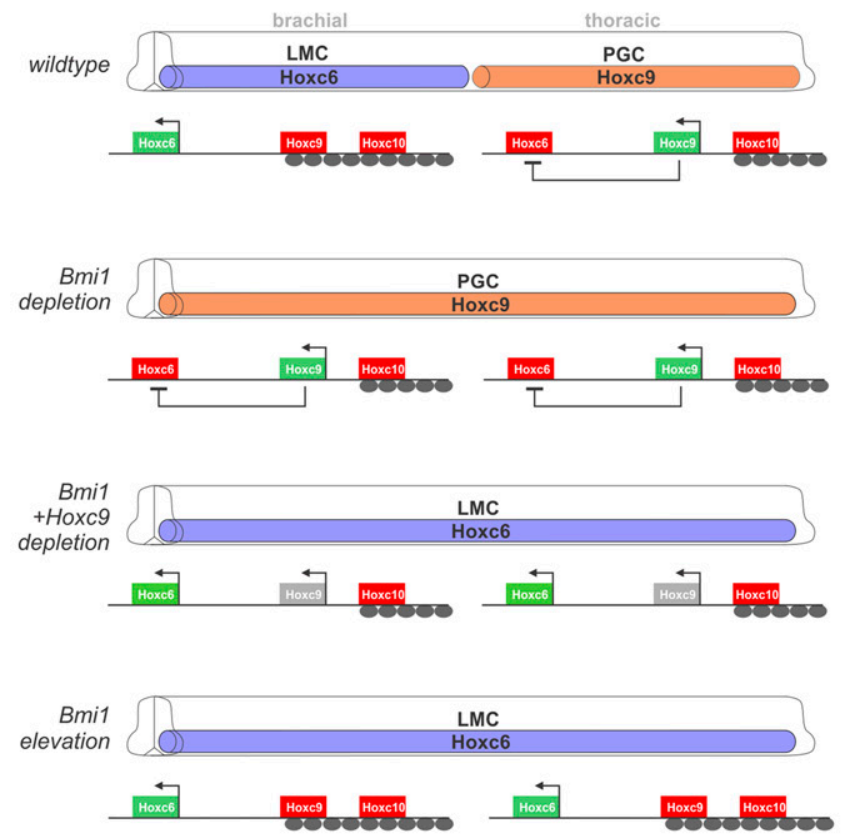

We found that both elevation of FGF8 signaling and loss of Bmil at brachial levels induce Hoxc9 and convert LMC MNs to a PGC fate. However, the progenitor pattern of Hoxc9 is unchanged under conditions of Bmil depletion, and unlike the effects FGF8 exposure, ectopic Hoxc9 is observed only just before the first post-mitotic MNs appear. Moreover, loss of the H3K27me3 mark from MN progenitors fails to alter Hox patterns in MNs, while postmitotic Bmil expression is sufficient to rescue early Bmil depletion. These observations point to a relatively late role for PRC1 to refine and maintain Hox patterns subsequent to early signaling gradients.

If Hox gene expression is initially set in neural progenitors, why might PRC1 act in early post-mitotic neurons? One possible scenario is that a temporal delay in PRC1-mediated repression might be used to ensure this restriction is developmentally linked to Hox cross-repressive activities. While the transcription of the Hoxc6, Hoxc9, and Hoxc10 genes are sequentially activated along the rostrocaudal axis at the progenitor phase (Dasen et al. 2003), Hox proteins are either weakly expressed or undetectable, with most proteins observed only in postmitotic neurons. Thus, Hox cross-repressive interactions can only emerge as MNs differentiate. For the case of Hoxc9, the restriction of its expression to thoracic levels has an essential role in creating a permissive environ-

\section{B Model for Hox gene regulation at the brachial-thoracic interface}

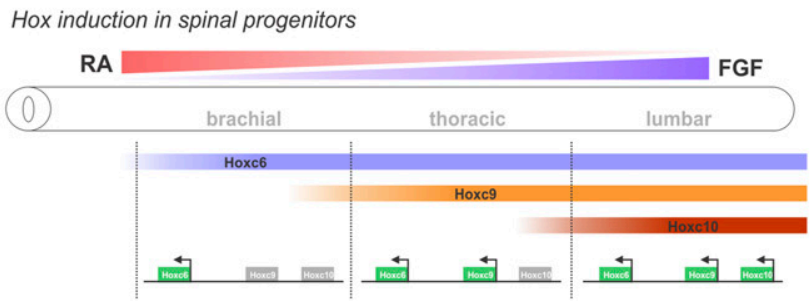

Establishment of anterior Hox boundaries by PRC1

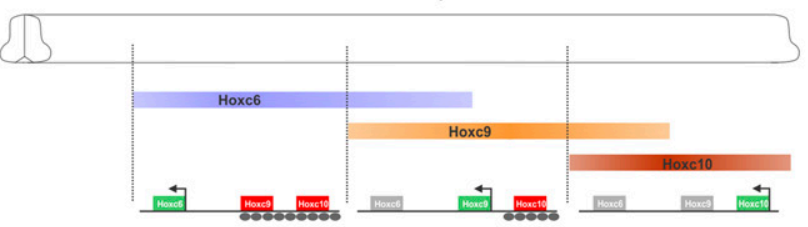

Establishment of posterior Hox boundaries through cross-repression

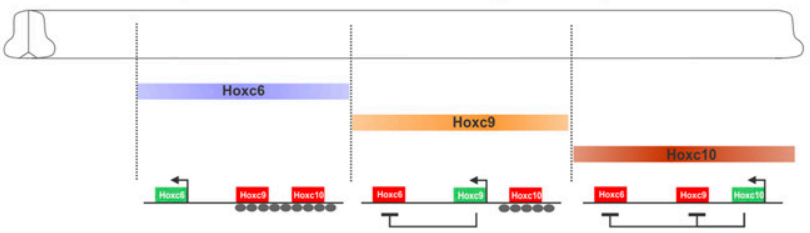

Figure 9. Model for PRCs in controlling Hox expression and MN columnar topography. (A) Summary of the effects of Bmil manipulations on Hox expression and columnar position at the brachial/thoracic boundary. Bmil depletion leads to ectopic Hoxc9 expression at thoracic levels and converts LMC MNs to a PGC fate. Loss of Hoxc6 is due to ectopic Hoxc9, as combined Hoxc9 and Bmil depletion rescues the phenotype. Elevation of Bmil at thoracic levels represses Hoxc9 and converts PGC MNs to an LMC fate. (B) Control of Hox gene expression in MNs by signaling gradients, PRCs, and cross-repression. Hox transcription is initiated in neural progenitors through the actions of positional gradients. Anterior boundaries are reinforced through the action of PRC1. Posterior boundaries are controlled through Hox cross-repressive interactions. 
ment for the emergence of the Hox4-Hox8 gene network required for LMC diversification (Jung et al. 2010). PRC1 action may therefore be deployed only at the time necessary to establish the final pattern of Hoxc9 (Fig. 9B).

\section{PcG function in vertebrate Hox gene regulation}

While the roles of PcG complexes in regulating Hox expression in Drosophila have been extensively studied, it is unclear whether the mechanisms of recruitment are preserved in vertebrates. In Drosophila, PcG complexes are recruited by PREs, conserved sequence elements that are capable of conferring PRC-dependent repression. In contrast, PRC1 and PRC2 appear to be broadly distributed across Hox loci in vertebrates (Bracken et al. 2006; Lee et al. 2006; Rinn et al. 2007), raising the question of whether their recruitment relies on PREs. Recently, the presence of a PRE within the HoxD locus that confers PcG-dependent repression has been reported (Woo et al. 2010). While the identification of additional PREs will facilitate analysis of Hox gene regulation in vertebrates, one confounding factor may be varied strategies used to regulate Hox genes in different cell types, and if additional PREs exist, they will have distinct functions within a particular cellular context.

Our results suggest that that in MNs, the Hoxc9 gene is particularly sensitive to the loss of PRC1 activity. We found that Bmil depletion fails to derepress Hoxc6 at cervical levels, and at thoracic levels, the majority of ectopic Hox $10^{+}$cells are found in the dorsal spinal cord. The apparent bias toward Hoxc9 regulation in $\mathrm{MNs}$ is consistent with microarray analysis of Bmi1 mutant neurospheres, showing Hox 9 genes as the most significantly derepressed, with few changes in other Hox paralogs (Molofsky et al. 2003). The regulation of Hoxc9 by Bmil may reflect a greater need to ensure a restricted domain of expression, as Hoxc9 has a unique role in controlling MN topography, and unlike most Hox genes, this activity is not compensated by other paralogs (Jung et al. 2010). The HoxC locus, like the HoxD cluster (Tschopp et al. 2012), may contain regulatory elements that are geared toward the regulation of only a subset of critical Hox genes in the context of neural tissue.

\section{PRC1 activity levels control Hox expression in MNs}

We observed that overexpression of Bmil at thoracic levels represses Hoxc9 and converts PGC MNs to an LMC fate. These effects are somewhat surprising, given that at this level of the spinal cord, the Hoxc9 gene does not carry the H3K27me3 mark thought to be necessary for PRC1 recruitment. Neighboring genes in the HoxC cluster, such as Hoxc10, do, however, contain the PRC2 mark at thoracic levels; thus, it is possible that the effects of PRC1 overexpression reflect an action of neighboring Hox genes on Hoxc9. One plausible scenario is that Bmil elevation retains Hoxc9 in association with transcriptionally inactive regions of the cluster. Alternatively, Bmil may act like a DNA-binding transcription factor, with a bias toward regulating Hoxc9. DNA-binding activities have been reported for Bmil and its homologs, and a Bmil response element has been shown to be present in the Hoxc9 gene (Meng et al. 2010).

Regardless of the precise mechanisms, the effects of Bmil depletion and overexpression indicate that in $\mathrm{MNs}$, HoxC genes are sensitive to the overall levels of PRC1 activities. If PRC1 activity levels are critical in defining Hox patterns, how might this system operate during normal development? The level and distribution of Bmil expression remains constant over the rostrocaudal axis, indicating that PRC1 activities are not set through graded expression. One possibility is that Bmil acts as a limiting factor that can grossly raise or lower the overall activity of PRC1, while additional factors are responsible for the graded activity of the complex over the rostrocaudal axis. One candidate for such a partner is a long noncoding RNA (lncRNA), which appears to regulate PRC binding at several loci, including Hox clusters (Spitale et al. 2011). Differential transcription of such an RNA over the rostrocaudal axis could have the effect of grading PRC recruitment to Hox loci. The recent identification of thousands of lncRNAs acting both in cis and in trans (Guttman et al. 2011) will confound defining whether they contribute to Hox gene regulation, and moreover, genetic evidence supporting an instructive role for lncRNAs is currently lacking (Schorderet and Duboule 2011). Nevertheless, if such a graded component exists, it would provide an attractive candidate for linking the early positional gradients to the chromatin modifications necessary for precisely controlling Hox patterns in the CNS.

\section{Materials and methods}

\section{ChIP assays}

Cervical, brachial, thoracic, and lumbar spinal cords were dissected, and tissues were homogenized in $1.1 \%$ formaldehyde using a dounce B homogenizer. Chromatin was extracted and fragmented by sonication. Chromatin extracts $(20 \mu \mathrm{g})$ were incubated overnight at $4^{\circ} \mathrm{C}$ with $4-5 \mu \mathrm{g}$ of either specific antibodies or species-matched immunoglobulins (IgGs). Protein A/G-agarose beads (Roche) were added for $2.5 \mathrm{~h}$ at $4^{\circ} \mathrm{C}$, and complexes were washed seven times with RIPA and eluted with $1 \%$ SDS. DNA-protein de-cross-linking was performed overnight at $65^{\circ} \mathrm{C}$ followed by RNase and then proteinase $\mathrm{K}$ treatment. DNA was purified via QIAprep spin columns (Qiagen). Hox promoter regions were amplified using SYBR Green PCR master mix (Applied Biosystems) and detected by quantitative PCR. Oligonucleotide sequences are provided in the Supplemental Material. Fold enrichments were calculated over IgG: Fold enrichment $=2^{-(\Delta \mathrm{Ct})}$, where $\Delta \mathrm{Ct}=(\mathrm{CtIP}-\mathrm{CtIgG})$. Fold enrichments over $10 \%$ input were similar to fold enrichment over IgG. The following antibodies were used: rabbit antiH3K27me3 (Millipore), rabbit anti-H3K4me3 (Millipore), mouse anti-Bmil (Millipore), and rabbit anti-mouse IgG (Millipore).

\section{In ovo electroporation}

Electroporation of plasmids and dsRNAs was performed as described (Dasen et al. 2005). To identify electroporated neurons, siRNAs (final concentration $8.5 \mathrm{mg} / \mathrm{mL}$ ) were combined with a nuclear LacZ expression plasmid (final concentration $0.5 \mathrm{mg} / \mathrm{mL}$ ). The target sequence against chick Bmi1 was $5^{\prime}$-AGAACAGA CUGGAACGAAAUU-3'. Results are representative of at least 
two electroporated embryos in which the electroporation efficiency in MNs was $>60 \%$. Quantification of the effects of gene manipulations is shown in Supplemental Table S1.

\section{In situ hybridization and immunohistochemistry}

In situ hybridization and immunohistochemistry were performed as described (Jung et al. 2010). GFP-labeled axons were visualized in projections of confocal Z-stacks (500-1000 $\mu \mathrm{m})$. Antibodies against Hox proteins, LIM HD proteins, and other proteins were generated as described (Dasen et al. 2005, 2008). Additional antibodies were used as follows: mouse anti-Bmil (1:600; Millipore), rabbit anti-GFP (1:1000; Invitrogen), rabbit anti-H3K27me3 (Millipore), and rabbit anti-EED (1:1000; Abcam). Quantification of protein levels was performed as previously described (Dasen et al. 2008).

\section{$R N A$ isolation and RT-PCR}

RNA was isolated from tissues via TRIzol LS reagent (Invitrogen) according to the manufacturer's instructions. First strand cDNA was synthesized from $\sim 100 \mathrm{ng}$ of RNA using the SuperScript II First Strand Synthesis system for RT-PCR (Invitrogen). cDNA was amplified using SYBR Green PCR master mix and detected by quantitative PCR. Fold enrichments were calculated over GAPDH: Fold enrichment $=2^{-(\Delta \mathrm{Ct})}$, where $\Delta \mathrm{Ct}=(\mathrm{CtHox} / \mathrm{Bmil}-$ CtGAPDH).

\section{Acknowledgments}

We thank Myungin Baek, Catarina Catela, and Denis Duboule for comments on the manuscript, and Steve Burden, Gord Fishell, and Jessica Treisman for discussions. We also thank Sean Morrison and Maarten van Lohuizen for Bmi1 mutants, and Alexander Tarakhovsky for the Ezh2 conditional allele. J.D. is supported by grants from the McKnight Foundation, Alfred P. Sloan, Project ALS, NYSTEM, HHMI and NIH R01 NS062822.

\section{References}

Akasaka T, van Lohuizen M, van der Lugt N, Mizutani-Koseki Y, Kanno M, Taniguchi M, Vidal M, Alkema M, Berns A, Koseki H. 2001. Mice doubly deficient for the Polycomb Group genes Mell8 and Bmil reveal synergy and requirement for maintenance but not initiation of Hox gene expression. Development 128: 1587-1597.

Akizu N, Estaras C, Guerrero L, Marti E, Martinez-Balbas MA. 2010. H3K27me3 regulates BMP activity in developing spinal cord. Development 137: 2915-2925.

Alkema MJ, van der Lugt NM, Bobeldijk RC, Berns A, van Lohuizen M. 1995. Transformation of axial skeleton due to overexpression of bmi-1 in transgenic mice. Nature 374: 724-727.

Boyer LA, Plath K, Zeitlinger J, Brambrink T, Medeiros LA, Lee TI, Levine SS, Wernig M, Tajonar A, Ray MK, et al. 2006. Polycomb complexes repress developmental regulators in murine embryonic stem cells. Nature 441: 349-353.

Bracken AP, Dietrich N, Pasini D, Hansen KH, Helin K. 2006. Genome-wide mapping of Polycomb target genes unravels their roles in cell fate transitions. Genes Dev 20: 1123-1136.

Brunk BP, Martin EC, Adler PN. 1991. Drosophila genes Posterior Sex Combs and Suppressor two of zeste encode proteins with homology to the murine bmi-1 oncogene. Nature 353: 351-353.
Dasen JS, Jessell TM. 2009. Hox networks and the origins of motor neuron diversity. Curr Top Dev Biol 88: 169-200.

Dasen JS, Liu JP, Jessell TM. 2003. Motor neuron columnar fate imposed by sequential phases of Hox-c activity. Nature 425: 926-933.

Dasen JS, Tice BC, Brenner-Morton S, Jessell TM. 2005. A Hox regulatory network establishes motor neuron pool identity and target-muscle connectivity. Cell 123: 477-491.

Dasen JS, De Camilli A, Wang B, Tucker PW, Jessell TM. 2008. Hox repertoires for motor neuron diversity and connectivity gated by a single accessory factor, FoxP1. Cell 134: 304-316.

Dessaud E, Yang LL, Hill K, Cox B, Ulloa F, Ribeiro A, Mynett A, Novitch BG, Briscoe J. 2007. Interpretation of the sonic hedgehog morphogen gradient by a termporal adaptation mechanism. Nature 450: 717-721.

Ezhkova E, Lien WH, Stokes N, Pasolli HA, Silva JM, Fuchs E. 2011. EZH1 and EZH2 cogovern histone H3K27 trimethylation and are essential for hair follicle homeostasis and wound repair. Genes Dev 25: 485-498.

Fasano CA, Phoenix TN, Kokovay E, Lowry N, Elkabetz Y, Dimos JT, Lemischka IR, Studer L, Temple S. 2009. Bmi-1 cooperates with Foxg1 to maintain neural stem cell selfrenewal in the forebrain. Genes Dev 23: 561-574.

Guttman M, Donaghey J, Carey BW, Garber M, Grenier JK, Munson G, Young G, Lucas AB, Ach R, Bruhn L, et al. 2011. lincRNAs act in the circuitry controlling pluripotency and differentiation. Nature 477: 295-300.

Hirabayashi Y, Suzki N, Tsuboi M, Endo TA, Toyoda T, Shinga J, Koseki H, Vidal M, Gotoh Y. 2009. Polycomb limits the neurogenic competence of neural precursor cells to promote astrogenic fate transition. Neuron 63: 600-613.

Jessell TM. 2000. Neuronal specification in the spinal cord: Inductive signals and transcriptional codes. Nat Rev Genet 1: 20-29.

Jung H, Lacombe J, Mazzoni EO, Liem KF Jr, Grinstein J, Mahony S, Mukhopadhyay D, Gifford DK, Young RA, Anderson KV, et al. 2010. Global control of motor neuron topography mediated by the repressive actions of a single hox gene. Neuron 67: 781-796.

Jurgens G. 1985. A group of genes controlling the spatial expression of the bithorax complex in Drosophila. Nature 316: 153-155.

Khalil AM, Guttman M, Huarte M, Garber M, Raj A, Morales DR, Thomas K, Presser A, Bernstein BE, van Oudenaarden A, et al. 2009. Many human large intergenic noncoding RNAs associate with chromatin-modifying complexes and affect gene expression. Proc Nat1 Acad Sci 106: 11667-11672.

Lee TI, Jenner RG, Boyer LA, Guenther MG, Levine SS, Kumar RM, Chevalier B, Johnstone SE, Cole MF, Isono K, et al. 2006. Control of developmental regulators by Polycomb in human embryonic stem cells. Cell 125: 301-313.

Lewis EB. 1978. A gene complex controlling segmentation in Drosophila. Nature 276: 565-570.

Mallo M, Wellik DM, Deschamps J. 2010. Hox genes and regional patterning of the vertebrate body plan. Dev Biol 344: 7-15.

Martin EC, Adler PN. 1993. The Polycomb group gene Posterior Sex Combs encodes a chromosomal protein. Development 117: 641-655.

Meng S, Luo M, Sun H, Yu X, Shen M, Zhang Q, Zhou R, Ju X, Tao W, Liu D, et al. 2010. Identification and characterization of Bmi-1-responding element within the human p16 promoter. J Biol Chem 285: 33219-33229.

Molofsky AV, Pardal R, Iwashita T, Park IK, Clarke MF, Morrison SJ. 2003. Bmi-1 dependence distinguishes neural 
stem cell self-renewal from progenitor proliferation. Nature 425: 962-967.

Rinn JL, Kertesz M, Wang JK, Squazzo SL, Xu X, Brugmann SA, Goodnough LH, Helms JA, Farnham PJ, Segal E, et al. 2007. Functional demarcation of active and silent chromatin domains in human HOX loci by noncoding RNAs. Cell 129: $1311-1323$.

Schorderet P, Duboule D. 2011. Structural and functional differences in the long non-coding RNA Hotair in mouse and human. PLoS Genet 7: e1002071. doi: 10.1371/journal.pgen. 1002071.

Schuettengruber B, Cavalli G. 2009. Recruitment of polycomb group complexes and their role in the dynamic regulation of cell fate choice. Development 136: 3531-3542.

Shirasaki R, Pfaff SL. 2002. Transcriptional codes and the control of neuronal identity. Annu Rev Neurosci 25: 251-281.

Simon JA, Kingston RE. 2009. Mechanisms of Polycomb gene silencing: Knowns and unknowns. Nat Rev Mol Cell Biol 10: 697-708.

Simon J, Chiang A, Bender W. 1992. Ten different Polycomb group genes are required for spatial control of the abdA and AbdB homeotic products. Development 114: 493-505.

Sing A, Pannell D, Karaiskakis A, Sturgeon K, Diabali M, Ellis J, Lipshitz HD, Cordes SP. 2009. A vertebrate polycomb response element governs segmentation of the posterior hindbrain. Cell 138: 885-897.

Soshnikova N, Duboule D. 2009. Epigenetic temporal control of mouse Hox genes in vivo. Science 324: 1320-1323.

Spitale RC, Tsai M-C, Chang HY. 2011. RNA templating the epigenome. Epigenetics 6: 539-543.

Struhl G. 1981. A gene product required for correct initiation of segmental determination in Drosophila. Nature 293: 36-41.

$\mathrm{Su} \mathrm{IH}$, Basavaraj A, Krutchinsky AN, Hobert O, Ullrich A, Chait BT, Tarakhovsky A. 2003. Ezh2 controls B cell development through histone $\mathrm{H} 3$ methylation and Igh rearrangement. Nat Immunol 4: 124-131.

Tschopp P, Christen AJ, Duboule D. 2012. Bimodal control of Hoxd gene transcription in the spinal cord defines two regulatory subclusters. Development 139: 929-939.

van der Lugt NM, Domen J, Linders K, van Roon M, RobanusMaandag E, te Riele H, van der Valk M, Deschamps J, Sofroniew M, van Lohuizen M, et al. 1994. Posterior transformation, neurological abnormalities, and severe hematopoietic defects in mice with a targeted deletion of the bmi-1 proto-oncogene. Genes Dev 8: 757-769.

van der Lugt NM, Alkema M, Berns A, Deschamps J. 1996. The Polycomb-group homolog Bmi-1 is a regulator of murine Hox gene expression. Mech Dev 58: 153-164.

van Lohuizen M, Frasch M, Wientjens E, Berns A. 1991. Sequence similarity between the mammalian bmi-1 protooncogene and the Drosophila regulatory genes Psc and Su(z)2. Nature 353: 353-355.

Woo CI, Kharchenko PV, Daheron L, Park PI, Kingston RE. 2010. A region of the human HOXD cluster that confers polycombgroup responsiveness. Cell 140: 99-110.

Yap KL, Li S, Munoz-Cabello AM, Raguz S, Zeng L, Mujtaba S, Gil J, Walsh MJ, Zhou M-M. 2010. Molecular interplay of the non-coding RNA ANRIL and methylated histone H3 lysine 27 by polycomb CBX7 in transcriptional silencing of INK4a. Mol Cell 38: 662-674.

Zhao J, Sun BK, Erwin JA, Song J-J, Lee JT. 2008. Polycomb proteins targeted by a short repeat RNA to the mouse $\mathrm{X}$-chromosome. Science 322: 750-756. 


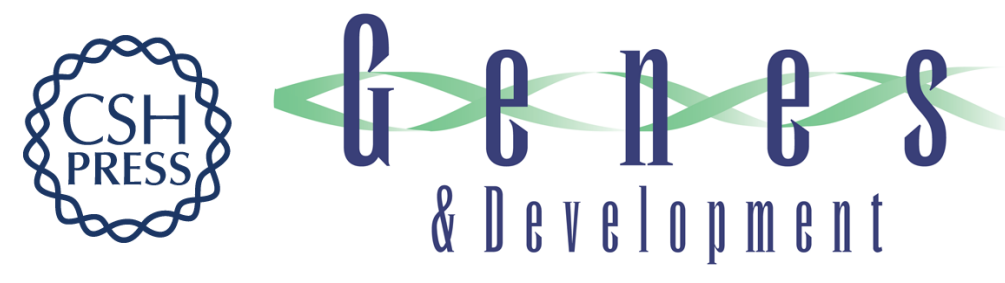

\section{Polycomb repressive complex 1 activities determine the columnar organization of motor neurons}

Molly G. Golden and Jeremy S. Dasen

Genes Dev. 2012, 26:

Access the most recent version at doi:10.1101/gad.199133.112

Supplemental
Material http://genesdev.cshlp.org/content/suppl/2012/09/27/26.19.2236.DC1

References This article cites 43 articles, 14 of which can be accessed free at: http://genesdev.cshlp.org/content/26/19/2236.full.html\#ref-list-1

License

Email Alerting

Service

Receive free email alerts when new articles cite this article - sign up in the box at the top right corner of the article or click here.

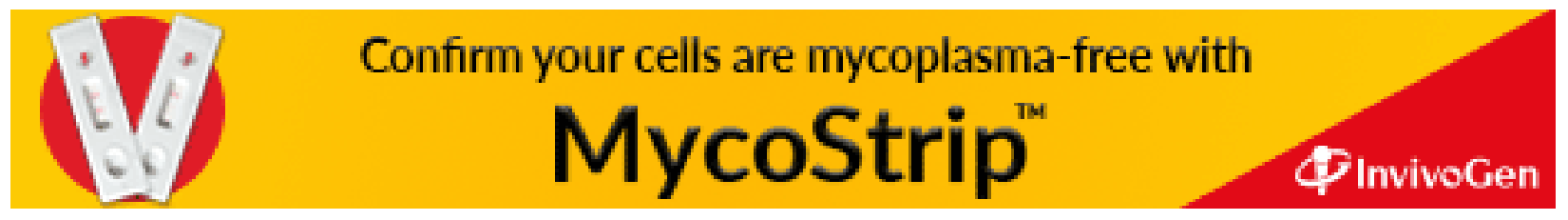

